\title{
A descriptive epidemiology of netball injuries during competition: a five year study
}

\author{
Diana Hopper*, Bruce Elliott + and Jenny Lalor $\neq$ \\ Curtin University of Technology, Western Australia: ${ }^{*}$ School of Physiotherapy, $¥$ Computing Centre; \\ t The University of Western Australia, Department of Human Movement;
}

\begin{abstract}
Objective - To investigate the relation between injury profiles - including assessment, treatment, severity, and the perceived reason for the injury - and participation in competitive netball.

Methods - Between 1985 and 1989, approximately 11228 netball players participated in a 14 week netball competition held at the major competitive centre in Western Australia; 608 netball players presented to the first aid room with an injury and were assessed and treated by the same physiotherapist and St John First Aid officer.

Results - The overall incidence rate during competition was $5.4 \%$, with more injuries occurring in the $A$ grade level of play. Ankle injuries (84\%) were most frequent, with $67 \%$ of these injuries diagnosed as lateral ligament sprains while a further $10 \%$ of players who suffered this classification of injury sustained a fracture to the ankle or foot. Few injuries occurred at the knee joint $(8.3 \%)$ and only $1.8 \%$ of these injuries were diagnosed as an injury to the anterior cruciate ligament. The direct probability of a netball players' risk estimate was 0.054 per person per match which implied that netball was a relatively safe game. Injuries sustained during practice were not included in this study.

Conclusions - Netball is a relatively safe game though the potential for injury increases with the level of competition. ( $\mathrm{Br} J$ Sports Med 1995; 29: 223-228)
\end{abstract}

Keywords : netball injuries; injury profiles; player characteristics; ankle injuries; severity

Throughout Australia netball is enjoyed by approximately 800000 registered players, the highest number of participants of any sport. Skilled A grade players in both senior and junior competitions have been found to be more susceptible to injuries than lower grade players. ${ }^{1}$ Lower limb injuries were most often reported, the ankle region being the predominant site $(58 \%)$. Other studies have investigated different levels of performance and confirmed that ankle injuries were the most frequent site of injury $\left(^{1-3}\right.$ and $\mathrm{O}^{\prime}$ Connor ST, unpublished data). Recently, Egger $^{4}$ reported that netball had the highest proportion of injuries (ankle $40 \%$, knee 20\%) when compared with other Australian sports including the different football codes, basketball, hockey, and cricket.

Although knee injuries occurred less frequently than ankle injuries ( $14 \%$ v 58\%), these injuries were con-

Address for correspondence: Dr Diana Hopper, Curtin University of Technology, School of Physiotherapy, Selby Street, Shenton Park, Western Australia, 6008, Australia. sidered more severe and required more referrals to physicians than other types of injury. ${ }^{1}$ Egger $^{4}$ was commissioned by the Australian government to investigate the causes, costs, and prevention programmes for sporting injuries of eight major team sports. This report found that knee injuries in sport accounted for $25 \%$ of all direct injury costs, with an estimate of $\$ 100$ million in 1990. In comparison ankle injuries cost substantially less, involving only $6 \%$ of all direct costs with an expenditure estimate of $\$ 25$ million.

One of the primary reasons advocated for lower limb netball injuries was related to incorrect landing techniques. ${ }^{1}$ Steele $^{2}$ recommended that all netball players, regardless of age, should incorporate specific training drills that encompassed landing techniques to ensure that players use correct body mechanics when landing, especially after striding forward to receive a pass. The purposes of this study were therefore to identify the current status and the changes over a five year period of: (1) the injury incidence rate and relative risk factors of netball injuries; (2) the injury profile including assessment, perceived reason for the of injury, treatment, and severity of injury associated with the year of participation, level of competition or body region; and (3) the injured player characteristics (position, time of injury, playing tactic, warm up training patterns) associated with the level of competition.

\section{Methods}

\section{Subjects}

The major winter netball competition is held for 14 weeks at the at Western Australia Netball Association Matthew's centre. Here players participated in a weekly competition ranging from A1 to D6 grades. During the five year period (1985 to 1989), 608 players presented to the first aid room with an injury out of an approximate total of 11228 players who competed at this centre. However, injuries sustained during practice were not included in this study. The overall mean age of the players presenting with an injury was $18.8( \pm 5.6)$ years.

\section{Sample size}

In 1985, 2576 netball players registered during this winter season. The number of players participating in 
this competition progressively declined each subsequent year, with 2331 players competing in 1986, 2254 in 1987, 2149 in 1988, and 1918 in 1989.

\section{Administration of the injury questionnaire}

When a netball player was injured during competition they presented to the first aid room. The player was evaluated by the physiotherapist and appropriate immediate care treatment was applied. The injury classification for this study was the same as the previous study by Hopper. ${ }^{1}$ An injury was therefore assessed if a player (a) required immediate treatment or (b) a body part presented with some degree of disability.

Minor injuries were treated and prophylactic strapping was applied, but these compliants were not included in this study. All injured players were asked to complete the first two pages of a three page questionnaire, divided into five categories, each with a different focus: general subject information, the occurrence of injury, incidence of injury, conditions when injuries occurred, and footwear used at the time of the injury. The third page of the questionnaire was completed by the physiotherapist, who assessed and recorded the severity classification of the injury ${ }^{5}$ (grade 1 , grade 2 , and grade 3 ), immediate presentation of the injury, initial treatment, and recommendations for further treatment. This three page questionnaire was based on the original document published by Hopper. ${ }^{1}$

\section{Analysis and treatment of the data}

Six hundred and eight players presented with an injury and filled out a questionnaire; however, some players neglected to complete a number of questions and therefore numerical variations in responses are evident. To determine the injury incidence rate, the injured players were divided by the total number of participating players. ${ }^{6}$

Data from the injury questionnaires were coded and stored on a main frame computer. The SPSS software was used to assess these data and to determine the frequency and cross tabulations using a Pearson $\chi^{2}$ test. Statistical significance for all analyses was set at the 0.05 level.

\section{Results and discussion}

Between 1985 and 1989, approximately 11288 players participated in winter netball competitions at the major Western Australia Netball centre and of this number 608 players reported to the first aid room with an injury. The overall injury incidence rate sustained in competition was therefore $5.4 \%$ (Table 1). However, when this injury incidence rate was calculated for each of the different levels of competition, the highest percentage was recorded for A grade ( $8.5 \%)$, followed by B grade $(5.2 \%), C$ grade $(4.3 \%)$, and $3.3 \%$ of players were injured in the lowest level of competition ( $\mathrm{D}$ grade). The direct probability of netball players risk estimate during competition was 0.054 per person per match.
Table 1. Injury incidence rate of netball injuries

\begin{tabular}{lcrrr}
\hline Grade & Injured & Uninjured & Total & $\begin{array}{c}\text { Injury incidence } \\
\text { rate }\end{array}$ \\
\hline A & 258 & 2766 & 3024 & $8.5 \%$ \\
B & 148 & 2722 & 2870 & $5.2 \%$ \\
C & 112 & 2506 & 2618 & $4.3 \%$ \\
D & 90 & 2626 & 2716 & $3.3 \%$ \\
Total & 608 & 10620 & 11228 & \\
\hline
\end{tabular}

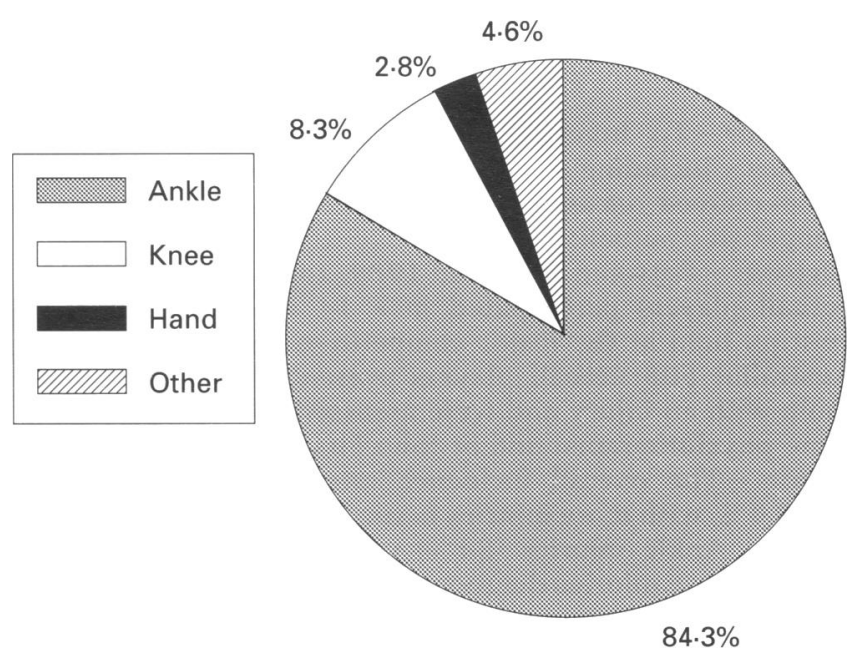

Figure 1. Site of injury.

The anatomical locations of the of netball injuries are shown in Figure 1. The most frequent site of injury was the ankle region $(84 \%)$. This percentage was higher than reported in previous netball studies. ${ }^{1-4}$ Over this five year period, the incidence of ankle injuries may be more representative of what actually occurs, as other studies have investigated either a specialised population of netball players or statistics were only recorded for one netball season. Other researchers, however, have confirmed that ankle injuries were the most common in sport. ${ }^{5} 7$

Figure 1 shows that the incidence of knee injuries was $8.3 \%$, which was similar to the $9.1 \%$ reported in a one day veteran tournament ${ }^{2}$ but different from the $15.2 \%$ found in a 14 week winter netball season. ${ }^{1}$ The percentage of hand injuries $(2.8 \%)$ was lower than recorded in the previous studies $\left(13.3 \%^{1}\right.$ and $\left.22.8 \%{ }^{2}\right)$. Injuries to the back region, muscle strains, and upper limb injuries were grouped under the "other" category. The $4.6 \%$ incidence for "other" injuries was less than than $13.3 \%^{1}$ and the $25 \%$ of injuries to the leg, thigh, back, or neck. ${ }^{2}$ These difference in hand and "other" injuries could be a result of the injury classification used in this study. Many of these injuries were treated, but they were considered minor and were not included in the data analysis.

Analysis of ankle injuries showed that $67 \%$ of injured players presented with lateral ligament complex sprains compared with $4.4 \%$ for the deltoid ligament (Table 2). 
Table 2. Diagnosis and frequency of netball injuries

\begin{tabular}{lrr}
\hline Injuries & Number & Percent \\
\hline Ankle & 288 & \\
ATFL & 67 & 47.4 \\
ATFL and CFL & 53 & 8.7 \\
ATFL, CFL, PTFL & 27 & 4.4 \\
Deltoid ligament & 5 & 0.8 \\
Bifurcate ligament & 4 & 0.7 \\
Spring ligament & 8 & 1.3 \\
Peroneal tears & 25 & 4.1 \\
Fracture of lateral malleolus & 9 & 1.5 \\
Fracture of medial malleolus & 4 & 0.7 \\
Fracture of cuboid/1st metatarsal & 23 & 3.8 \\
Fracture base of 5th metatarsal & & \\
Knee & 11 & 1.8 \\
Anterior cruciate ligament & 16 & 2.6 \\
Meniscus (lateral and/or medial) & 9 & 1.5 \\
Medial collateral ligament & 6 & 1.0 \\
Lateral collateral ligament & 8 & 1.3 \\
Patellar subluxed or dislocated & & \\
Muscle & 11 & 1.8 \\
Lower leg muscle strain & 3 & 0.5 \\
Lower back muscle strain & 5 & 0.8 \\
Quadriceps haematoma & & \\
Upper limb & 3 & 0.5 \\
Shoulder joint-rotator cuff & 6 & 1.0 \\
Elbow ligament/dislocation/fracture & & \\
Finger & 17 & 2.8 \\
Digital joint sprain/fracture & 608 & \\
Grand total & & \\
\hline ATEL anter & & \\
\hline
\end{tabular}

ATFL $=$ anterior talofibular ligament, $\mathrm{CFL}=$ calcaneofibular ligament, PTFL $=$ posterior talofibular ligament.

The lateral ligament complex has been found to be the most frequently injured single structure of the body in several other sports. ${ }^{5,7,8}$

While the majority of ankle injuries were sprains, approximately $10 \%$ of the netball players presented with fractures to the lateral $(4 \%)$ and medial malleoli $(1.5 \%)$ and to the base of the fifth metatarsal $(3.8 \%)$ or the first metatarsal $(0.7 \%)$. These fractures were considered serious as they required medical assessment and treatment. Depending upon the type of the fracture, immobilisation of the lower leg in a cast was recommended, while in some cases operative procedures were required. ${ }^{5,} 9$

Fewer injuries occurred at the knee joint than in a previous survey. ${ }^{1}$ The type of injury was relatively evenly distributed among common knee problems, with $2.6 \%$ of players sustaining medial or lateral meniscal injuries and $2.5 \%$ of injured players presenting with a collateral ligament sprain. A small percentage of players was diagnosed with an anterior cruciate ligament problem (1.8\%); however, this type of injury was considered difficult to diagnose. ${ }^{10}$ Although the results of this study may have underestimated the incidence of anterior ligament problems, the conservative or surgical management was lengthy and rehabilitation expensive. ${ }^{4}$

The diagnosis of hand and finger injuries $(2.8 \%)$ mainly involved joint ligamentous sprains $(2.1 \%)$ and fractures $(0.7 \%)$. "Other" types of injuries $(4.6 \%)$ varied, with players reporting lower leg strain, quadriceps haematoma, rotator cuff shoulder problems, an elbow joint dislocation, a radial fracture, and back problems.
When all these diagnoses were regrouped into an injury tissue classification, $81 \%$ of players suffered ligamentous injuries, $11 \%$ sustained a fracture, and $8 \%$ of players presented with muscle or soft tissue problems.

Irrespective of the level of competition, injuries to the ankle region were significantly the most common with approximately $65 \%$ presenting as new injuries and only $35 \%$ as recurring chronic problems (Table 3). Of all new injuries incurred in competition those to the ankle region were again most prevalent $(81.5 \%)$ compared with injuries to the knee joint (9.5\%). More than $80 \%$ of knee injuries were new injuries and only $20 \%$ reported a recurring knee problem. This low percentage of reinjury may suggest that many players who had sustained a knee injury withdrew from further participation in netball.

Although Table 3 shows that there was a significant association between the mechanism of injury and body region, two blank cells occurred because hand injuries were not related to incorrect landing or the slipped/ tripped category. However, another $\chi^{2}$ table was calculated with the hand region deleted and the results $\left(\chi^{2} 40.49, \mathrm{df}=6, \mathrm{P}<0.00\right)$ indicated that there was still a significant association between mechanism of injury and body region. More than $38 \%$ of the players considered that incorrect landing was responsible for their ankle and knee injuries. Hopper ${ }^{1}$ found that incorrect landing, slipping, or tripping while moving were considered the main causes for players' injuries. Another study reported that over half of the ankle injuries sustained were caused by intrinsic factors such as an awkward landing ( $\mathrm{O}^{\prime}$ Connor ST, unpublished data). In contrast, Steele, ${ }^{2}$ who investigated veteran netball players, found that an injury was more likely to occur when a player was moving in a forward direction in anticipation of catching or deflecting a ball, although the body region was not specially identified.

More ankle/foot injuries occurred on the right side (59\%) compared with the left side of the body $(41 \%)$. However, a similar number of knee injuries was reported on the left side (53\%) and the right side ( $47 \%$ ) (Table 3).

There was a significant association between severity and body region, with more injuries occurring at the ankle and foot region ( $86 \%$ ) compared with the knee $(5 \%)$, hand $(4 \%)$, and "other" $(5 \%)$ body regions. The majority of players suffered either a minor grade 1 ankle sprain $(43.5 \%)$ or a more severe grade 2 ankle injury (44.5\%). Knee injury patterns were different, with $55.3 \%$ of players suffering from a severe grade 2 injury. Where a player experienced a total ligamentous rupture, dislocation, or fracture, a grade 3 classification was assigned to these injuries. A similar number of these serious grade 3 injuries was recorded for both ankle $(12 \%)$ and knee regions ( $13.1 \%)$. All players with grade 2 and grade 3 injuries were advised to seek further medical assessment. To summarise, when the body regions were combined, $44 \%$ of the players presented with a grade 1 injury, $43 \%$ with a more severe grade 2 injury, and $13 \%$ suffered the most severe grade 3 injury or fracture. A grade players recorded more severe grades of injury than players in the lower grades of competition. 
Netball injuries: a 5 year study: D Hopper et al.

Table 3. Injury profiles by body region

\begin{tabular}{|c|c|c|c|c|c|c|}
\hline & Ankle/foot & Knee & Hand & Other & $n$ & $\chi^{2}$ \\
\hline \multicolumn{7}{|l|}{ Injury type } \\
\hline New & $\begin{array}{r}81.5 \\
(65.4)\end{array}$ & $\begin{array}{r}9.5 \\
(81.3)\end{array}$ & $\begin{array}{r}3.4 \\
(82.4)\end{array}$ & $\begin{array}{r}5.6 \\
(85.2)\end{array}$ & 409 & $\begin{array}{c}10.70 \\
d f=3\end{array}$ \\
\hline Chronic & $\begin{array}{r}91.7 \\
(34.6)\end{array}$ & $\begin{array}{c}4.7 \\
(18.7)\end{array}$ & $\begin{array}{c}1.6 \\
(17.6)\end{array}$ & $\begin{array}{r}2.0 \\
(14.8)\end{array}$ & 192 & $P=0.01^{*}$ \\
\hline $\mathrm{n}$ & 509 & 48 & 17 & 27 & 601 & \\
\hline \multicolumn{7}{|l|}{ Injury mechanism } \\
\hline Player contact & $\begin{array}{r}76.0 \\
(20.3)\end{array}$ & $\begin{array}{r}9.0 \\
(24.0)\end{array}$ & $\begin{array}{c}6.0 \\
(47.1)\end{array}$ & $\begin{array}{r}9.0 \\
(48.0)\end{array}$ & 134 & $\begin{array}{c}47.46 \\
d f=9\end{array}$ \\
\hline Incorrect landing & $\begin{array}{r}90.4 \\
(41.4)\end{array}$ & $\begin{array}{r}8.3 \\
(38.0)\end{array}$ & - & $\begin{array}{r}1.3 \\
(12.0)\end{array}$ & 230 & $P=0.00^{*}$ \\
\hline Slip/stop & $\begin{array}{r}89.1 \\
(24.5)\end{array}$ & $\begin{array}{r}8.0 \\
(22.0)\end{array}$ & - & $\begin{array}{r}2.9 \\
(16.0)\end{array}$ & 138 & \\
\hline Other & $\begin{array}{r}75.0 \\
(13.8)\end{array}$ & $\begin{array}{c}8.7 \\
(16.0)\end{array}$ & $\begin{array}{r}9.8 \\
(52.9)\end{array}$ & $\begin{array}{r}6.5 \\
(24.0)\end{array}$ & 92 & \\
\hline $\mathrm{n}$ & 502 & 50 & 17 & 25 & 594 & \\
\hline \multicolumn{7}{|l|}{ Side of injury } \\
\hline Right side & $\begin{array}{r}86.9 \\
(59.2)\end{array}$ & $\begin{array}{r}6.3 \\
(46.8)\end{array}$ & $\begin{array}{r}2.8 \\
(58.8)\end{array}$ & $\begin{array}{r}4.0 \\
(51.9)\end{array}$ & 352 & $\begin{array}{c}3.13 \\
\mathrm{df}=3\end{array}$ \\
\hline Left side & $\begin{array}{r}82.4 \\
(40.8)\end{array}$ & $\begin{array}{r}9.8 \\
(53.2)\end{array}$ & $\begin{array}{c}2.7 \\
(41.2)\end{array}$ & $\begin{array}{r}5.1 \\
(48.1)\end{array}$ & 256 & $P=0.37$ \\
\hline $\mathrm{n}$ & 517 & 47 & 17 & 27 & 608 & \\
\hline \multicolumn{7}{|l|}{ Severity } \\
\hline Grade 1 & $\begin{array}{r}86.1 \\
(43.5)\end{array}$ & $\begin{array}{r}4.9 \\
(31.6)\end{array}$ & $\begin{array}{r}4.1 \\
(58.8)\end{array}$ & $\begin{array}{r}4.9 \\
(63.2)\end{array}$ & 244 & $\begin{array}{c}13.89 \\
\mathrm{df}=6\end{array}$ \\
\hline Grade 2 & $\begin{array}{r}88.8 \\
(44.5)\end{array}$ & $\begin{array}{c}8.7 \\
(55.3)\end{array}$ & $\begin{array}{r}1.2 \\
(17.6)\end{array}$ & $\begin{array}{r}1.3 \\
(15.8)\end{array}$ & 242 & $P=0.03^{*}$ \\
\hline Grade 3/fracture & $\begin{array}{r}81.1 \\
(12.0)\end{array}$ & $\begin{array}{c}7.7 \\
(13.1)\end{array}$ & $\begin{array}{r}5.6 \\
(23.6)\end{array}$ & $\begin{array}{r}5.6 \\
(21.0)\end{array}$ & 71 & \\
\hline $\mathrm{n}$ & 483 & 38 & 17 & 19 & 557 & \\
\hline \multicolumn{7}{|l|}{ Initial treatment } \\
\hline Ice/rest & $\begin{array}{r}85.9 \\
(31.4)\end{array}$ & $\begin{array}{r}5.4 \\
(20.4)\end{array}$ & $\begin{array}{r}1.2 \\
(5.9)\end{array}$ & $\begin{array}{c}15 \\
(53.6)\end{array}$ & 185 & $\begin{array}{c}14.32 \\
d f=3\end{array}$ \\
\hline Composite & $\begin{array}{r}83.7 \\
(68.8)\end{array}$ & $\begin{array}{r}9.4 \\
(79.6)\end{array}$ & $\begin{array}{r}3.8 \\
(94.1)\end{array}$ & $\begin{array}{r}3.1 \\
(46.4)\end{array}$ & 416 & $P=0.00^{*}$ \\
\hline $\mathrm{n}$ & 507 & 49 & 17 & 28 & 601 & \\
\hline \multicolumn{7}{|l|}{ Further treatment } \\
\hline Home programme/advice & $\begin{array}{r}90.5 \\
(57.9)\end{array}$ & $\begin{array}{r}3.1 \\
(20.0)\end{array}$ & $\begin{array}{c}2.7 \\
(52.9)\end{array}$ & $\begin{array}{r}3.7 \\
(42.9)\end{array}$ & 328 & $\begin{array}{c}28.97 \\
d f=6\end{array}$ \\
\hline $\begin{array}{l}\text { Referral to physician } \\
\text { or physiotherapist }\end{array}$ & $\begin{array}{r}76.8 \\
(27.1)\end{array}$ & $\begin{array}{c}14.9 \\
(54.0)\end{array}$ & $\begin{array}{r}2.2 \\
(23.6)\end{array}$ & $\begin{array}{r}6.1 \\
(39.2)\end{array}$ & 181 & $P=0.00^{*}$ \\
\hline Referral to hospital & $\begin{array}{r}77.8 \\
(15.0)\end{array}$ & $\begin{array}{c}13.1 \\
(26.0)\end{array}$ & $\begin{array}{r}4.0 \\
(23.5)\end{array}$ & $\begin{array}{r}5.1 \\
(17.9)\end{array}$ & 99 & \\
\hline $\mathrm{n}$ & 513 & 50 & 17 & 28 & 608 & \\
\hline
\end{tabular}

* Significant at the 0.05 level.

Row percentages no brackets: column percentages in brackets.

The level of initial treatment was significantly associated with the specific area of the body. A mean of $69 \%$ of the players, irrespective of the injured area, received composite treatment with ice followed by a compression bandage, strapping, or splint, while $31 \%$ of the players only required the application of ice or rest (Table 3). After the completion of treatment, each player was given a handout which outlined a programme to be completed at home and included cold therapy and a graded exercise regimen.

Irrespective of where the injury occurred, further treatment was significantly associated with the different body regions. Fifty four percent of the injured players received advice and home programmes, $30 \%$ were advised to visit a doctor or a physiotherapist, and $16 \%$ were referred to a hospital casualty department. For ankle injuries, $58 \%$ of the players were given advice and a home programme and only $15 \%$ were referred to the hospital. Conversely for knee injuries only $20 \%$ of the players received advice and a home programme, with $54 \%$ being referral to a doctor or a physiotherapist, while $27 \%$ were referred to a hospital. These findings confirmed the claims by Egger ${ }^{4}$ who stated that $25 \%$ of all direct injury costs were related to knee injuries, and that ankle injuries $(6 \%)$ accounted for substantially less.

The game of netball is divided into four 15 minute quarters. In the first quarter more injuries occurred and progressively fewer occurred in the subsequent quarters of play. Overall, more injuries were reported for defensive players, particularly those in goal defence (Figure 2). Players were requested to nominate the approximate time in the quarter when the injury occurred. More injuries (46\%) were sustained in the middle time frame, between the 6th and the 10th minute of each quarter of play. Both the centre $(19 \%)$ and goal defence $(19 \%)$ positions reported an equal number of 


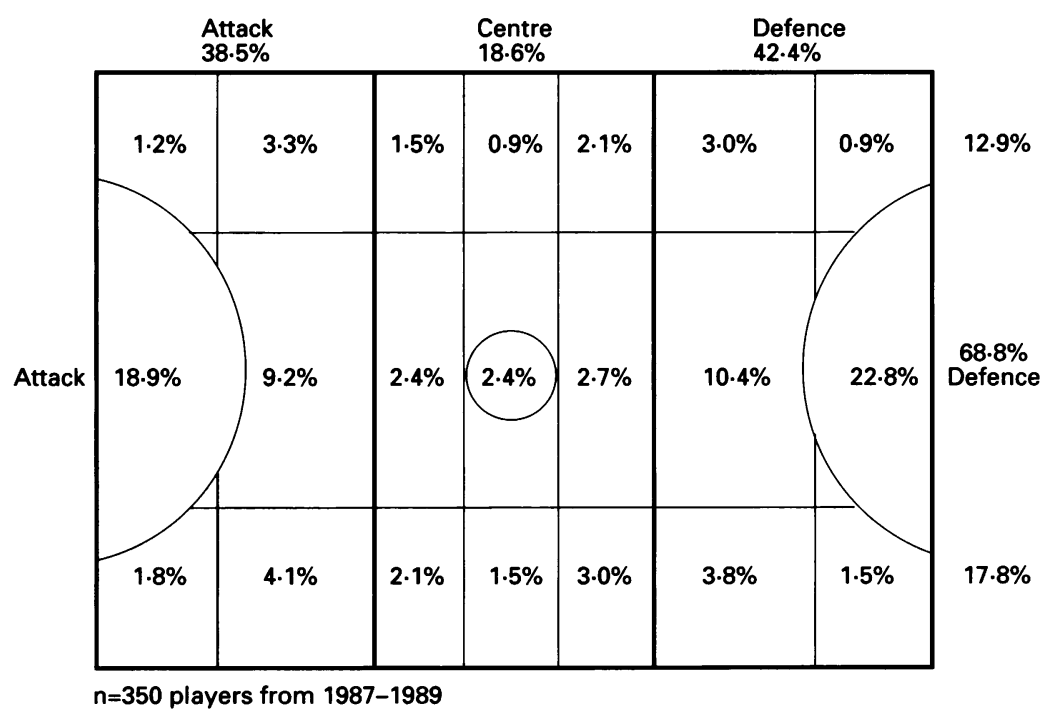

Figure 2. Location of injury on the netball court.

Table 4. Playing conditions by grade (values are percent).

\begin{tabular}{|c|c|c|c|c|c|c|}
\hline & A grade & $B$ grade & C grade & $D$ grade & $n$ & $\chi^{2}$ \\
\hline \multicolumn{7}{|l|}{ Playing tactic } \\
\hline Attacking & 46.4 & 23.1 & FS40 20.5 & 10.0 & 239 & 9.35 \\
\hline Defending & 39.2 & 25.7 & 17.0 & 18.1 & 342 & $\mathrm{df}=3$ \\
\hline $\mathrm{n}$ & 245 & 143 & 107 & 86 & 581 & $P=0.02^{*}$ \\
\hline \multicolumn{7}{|l|}{ Warm up } \\
\hline Yes & 46.3 & 23.2 & 17.2 & 13.3 & 525 & 29.14 \\
\hline$n$ & 250 & 140 & 106 & 88 & 584 & $P=0.00^{*}$ \\
\hline \multicolumn{7}{|l|}{ Length of warm up } \\
\hline $5 \mathrm{~min}$ & 30.6 & 23.1 & 24.4 & 21.9 & 160 & 59.39 \\
\hline $10 \mathrm{~min}$ & 37.3 & 29.2 & 21.1 & 12.4 & 161 & $\mathrm{df}=9$ \\
\hline $15 \mathrm{~min}$ & 62.9 & 21.0 & 8.4 & 7.7 & 143 & $P=0.00^{*}$ \\
\hline Other & 68.5 & 16.7 & 11.1 & 3.7 & 54 & \\
\hline$n$ & 236 & 123 & 91 & 68 & 518 & \\
\hline \multicolumn{7}{|l|}{ Training frequency } \\
\hline Twice & 54.2 & 19.4 & 15.3 & 11.1 & 72 & $d f=6$ \\
\hline Three times or more & 73.5 & 14.7 & 5.9 & 5.9 & 34 & $P=0.01^{*}$ \\
\hline $\mathrm{n}$ & 237 & 125 & 96 & 69 & 527 & \\
\hline \multicolumn{7}{|l|}{ Training duration } \\
\hline $1 \mathrm{~h}$ & 25.2 & 25.9 & 27.8 & 21.1 & 147 & 50.55 \\
\hline $1-2 \mathrm{~h}$ & 55.5 & 22.6 & 12.8 & 9.1 & 265 & $d f=6$ \\
\hline $3 \mathrm{~h}$ or more & 69.6 & 18.2 & 6.1 & 6.1 & 33 & $P=0.00^{*}$ \\
\hline$n$ & 207 & 104 & 77 & 57 & 445 & \\
\hline \multicolumn{7}{|l|}{ Other sports } \\
\hline Yes & 47.9 & 26.7 & 17.1 & 8.3 & 217 & 1.34 \\
\hline No & 46.3 & 23.2 & 18.3 & 12.2 & 82 & $\mathrm{df}=3$ \\
\hline$n$ & 142 & 77 & 52 & 28 & 299 & $P=0.72$ \\
\hline
\end{tabular}

*Significant at the 0.05 level.

injuries occurring in this time frame. There was no significant association $\left(\chi^{2} 20.01, \mathrm{df}=18, \mathrm{P}>0.05\right)$ between the seven different playing positions and time of injury. Therefore players from any positions have an equal probability of being injured at any stage of the match. These results were similar to other research findings ( ${ }^{1,2}$ and $\mathrm{O}^{\prime}$ Connor ST, unpublished data).

Each player recorded the playing tactic used at the time of injury. Table 4 shows that there was a significant association between playing tactic and grade of play.
Approximately $59 \%$ of the players reported that they were using defensive strategies at the time of injury in all levels of competition. When the location of the injury on the netball court was analysed, approximately $42 \%$ of injuries occurred in the defensive section of the court compared with $39 \%$ in the attack section and 19\% in the central area (Figure 2). Players defending a pass in the defensive goal circle $(23 \%)$ were more likely to be injured when compared with other positions on the court. 
Overall, $90 \%$ of the injured players warmed up before competition, with the majority ( $97 \%$ ) of $A$ grade players participating in some form of warmup compared with approximately $80 \%$ of players who participated in a warmup in the lower levels of competition (Table 4). Hopper ${ }^{1}$ had reported previously that only $70 \%$ of injured players performed a warmup routine, while Steele' $\mathrm{s}^{2}$ results showed that $47.5 \%$ of the veteran netball players did not participate in a prematch warmup. Steele ${ }^{2}$ further suggested that the high incidence of ligamentous and muscle injuries may have been attributed to this absence of a warmup routine.

Eighty per cent of the injured players trained at least once a week, with $17 \%$ of A grade players training at least twice a week and some of these players (11\%) being required to train three or more times a week. There was a significant association between the duration of training and level of competition, with $60 \%$ of players training between one and two hours per week. Most A grade players (70\%) trained between two to three hours per session. This duration altered according to level of competition, with the lower grade players training for shorter periods. Hopper ${ }^{1}$ reported similar levels, with $70 \%$ of players training once a week and most players ( $85 \%$ ) training between one and two hours at each session.

The majority of netball players were committed to once a week training session with a competitive match on Saturday. However, many these players $(73 \%)$ reported that they participated in other sports besides netball. When Steele ${ }^{2}$ surveyed veteran netball players, $77.3 \%$ reported that they were regularly involved in activities other than netball. Therefore it appears that many netball players vary their physical efforts, participating in a diverse range of sporting activities.

\section{Conclusions}

On the basis of the results obtained in this study, the following conclusions seem warranted:

(1) The injury incidence rate during competition for the different levels of play was higher for $A$ grade players $(8.5 \%)$ who recorded the most injuries, followed by B grade $(5.2 \%)$, C grade $(4.3 \%)$, and D grade $(3.3 \%)$.

(2) The most common site of injury was the ankle $(84 \%)$ followed by knee $(8 \%)$, hand $(3 \%)$, and "other" (5\%) areas of the body.

(3) Approximately $67 \%$ of ankle injuries were diagnosed as lateral ligament complex sprains, with $10 \%$ of players presenting with fractures of either malleolus or tarsal bones. Most of the knee joint injuries involved ligamentous and meniscal structures. Few players $(1.8 \%)$ were diagnosed with either a partial tear or complete rupture of an anterior cruciate ligament.

(4) Injury severity patterns for ankle and knee injuries were different. More players (55.3\%) suffering from grade 2 knee injuries compared with $44.5 \%$ for this level of injury to the ankle region. Referral to a casualty ward of a hospital showed that knee $(26 \%)$ injuries were more frequent than ankle $(15 \%)$ injuries.

(5) Defensive players were more susceptible to injury, especially when playing the position of goal defence.

To summarise, the direct probability of a netball player's risk estimate during competition was 0.054 per person per match, which indicated that netball was a relatively safe game where the potential for injury increased with the level of competition.

\section{Acknowledgements}

The authors would like to express their appreciation to the Western Australian Netball Association; to the St John's First Aid officer, Anne Cable; to the physiotherapists Therese Lloyd, Martin Podson, Judith Rodriguez, Carol Carmundie, Julie Pynt; and to Curtin University of Technology for their financial support. A special thanks is extended to all netball players who without their participation, this study would not have been realised.

\section{References}

1 Hopper D. A survey of netball injuries and conditions related to these injuries. Aust J Physiother 1986; 32 : 231-9.

2 Steele JR. Biomechanical factors affecting performance in netball. Implications for improving performance and injury reduction. Sports Med 1990; 10: 88-102.

3 Purdam C. A survey of netball and basketball injuries. Excel 1987; 3: 9-11.

4 Egger G. Sports injuries in Australia. Causes,costs and prevention Centre for Health Promotion and Research, 1990.

5 Reid DC. Sports injury assessment and rehabilitation. New York: Churchill Livingstone, 1992.

6 Last JM. A dictionary of epidemiology. New York: Oxford University Press, 1988.

7 Garrick JG, Webb DR. Sports injuries: diagnosis and management. Philadelphia: WB Saunders, 1990.

8 Garrick JG. The frequency of injury, mechanism of injury and epidemiology of ankle sprains. Am J Sports Med 1977; 5: 241-2.

9 Yablon IG, Heller FG, Shouse L. The key role of the lateral malleolus in displaced fractures. J Bone Joint Surg 1977; 59A: 169-73.

10 Noyes FR, Mooar PA, Matthews DS, Butler DL. The symptomatic anterior cruciate deficient knee. Part 1. The long-term functional disability in athletically active individuals. J Bone Joint Surg 1983; 65A: $154-62$. 